\title{
Technical Efficiency And Its Determinants: An Empirical Study Of Surgical Instruments Cluster Of Pakistan
}

\author{
Amir Ikram, Xi' an Jiaotong University, China \\ Qin Su, Xi' an Jiaotong University, China \\ Muhammad Asif Sadiq, GC University Lahore, Pakistan
}

\begin{abstract}
The empirical study was conducted to examine the technical efficiency of SMEs in the export-oriented surgical instruments cluster of Sialkot, Pakistan. Stratified sampling method was used to collect data via survey questionnaire from 70 SMEs, listed at Census of Manufacturing Industries and Federal Bureau of Statistics, for the period 2012-2013. For data analysis, Cobb-Douglas production function and an inefficiency model based on stochastic frontier approach, estimated through OLS method, were employed. The study draws on its inferences from both the qualitative and quantitative data. There was widespread prevalence of technical inefficiencies and provision of indirect inputs, labor, material and energy found to be significant determinants of technical efficiency. Moreover, this export-oriented industrial cluster is shown to experience constant returns to scale. Provision of proximate specialized surgical instruments and raw-material market is recommended. We also put forward clusterspecific suggestion of pursuing of 'triple-helix +1 ' model, whereby local community is integrated with the traditional triple helix forces. It was further advocated that by reducing the prevailing technical inefficiency in this urbanization economy, productivity can be enhanced by as much as $5.6 \%$. Stakeholders are advised to proactively indoctrinate themselves with the additive manufacturing of surgical instruments. Broader implications for clusterbased industries are also discussed.
\end{abstract}

Keywords: Technical Efficiency; Industrial Cluster; SMEs; Cobb-Douglas Production Function; Additive Manufacturing

\section{INTRODUCTION}

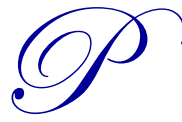

akistan has experienced the existence of numerous industrial clusters. Its eastern city of Sialkot is distinctive in a sense that it bestows two industrial clusters that serve as rare examples of reliable export successes even in the turbulent economic era, namely surgical instruments cluster and sports cluster. Emergence of majority of these clusters can be traced back to historical events. Our focus for this study is surgical instruments cluster of Sialkot. There is traditional and social perspective to it and its evolution can be traced back to historical events. The artisans of domestic community had the inherited skill of making swords and knives, but the beginning of 19th century witnessed a changeover when the doctors of American Mission Hospital gave them the opportunity to repair and imitate scalpels and other related instruments. This replication worked a long way and shifted the hands towards making life-saving instruments from lethal items (Ahmad, 2010). The birth of Sialkot's surgical cluster has been partly explained by U.S. economist Krugrnan (1991), who rightly describes it as "historic accident". In 1905, some broken surgical equipment at the American Mission Hospital in Sialkot presented an opportunity to local craftsmen to furnish their skills. They gradually started manufacturing replicas of originals with the assistance of hospital staff. Gradually, orders were received from other mission hospitals in British India. By 1920, Sialkot was exporting to most parts of the then British Empire and also supplied surgical instruments to the Allied forces in World War II. In order to institutionalize surgical instruments sector and provide common facilities to the manufacturers, Metal Industry Development Center (MIDC) was established by the British Government established back in 1941 and it helped the industrial transition from manufacturing basic metal products to precision surgical instrument (Ahmed, 2010). Surgical Instruments Manufacturers Association of Pakistan (SIMAP) was established in 1958 with the goal of protecting and promoting the inherited artisanship of surgical instruments 
manufacturing. SIMAP established Sialkot Material Testing Laboratory (SIMTEL) in 2001, under the collaborative initiative of Food and Drug Administration of USA and Trade Development Authority of Pakistan, in order to enhance quality and export competitiveness of the cluster. (Surgical Instruments Manufacturers Association of Pakistan [SIMAP], 2015).

After its inception in 1947, Pakistan inherited 17 registered enterprises manufacturing surgical instruments in Sialkot. Pakistan duly capitalized on this artisanship-oriented cluster and now it exports surgical instruments of the highest quality to over 140 countries around the world; USA, Germany and United Kingdom being the leading importers and buy as much as 50\% of the surgical instruments of the cluster (Ahmed, 2010; Nadvi, 1999a; Pakistan Tourism Development Corporation [PTDC], 2013). The cluster comprises more than 2500 SMEs and employs about 50,000 workers. Though this cluster primarily thrives upon small and medium enterprises, but is of paramount importance considering its contributions to international and domestic markets. More than 5000 different types of instruments are being manufactured in Sialkot (Ahmed, 2010). Exports for surgical instruments increased from 310.26 million US\$ in 2014 to 313.36 million US\$ in 2015 (SIMAP, 2015), and surgical instruments exports statistics are also exhibiting a positive trend for the last decade - 2004 to 2014 (UN Comtrade Database, 2014). Despite encompassing such prospective industrial clusters, it is astonishing to see that Pakistan has slipped further to $138^{\text {th }}$ place in 2016 from $128^{\text {th }}$ in 2015 in the Distance-to-Frontier ranking of World Bank (World Bank's Doing Business report, 2016). Though vastly contributing in exports and generating numerous success stories, the industrial cluster of surgical instruments is representative of the sad state of affairs prevalent in the economy. The empirical studies of such spawning industrial clusters will helpful in providing pragmatic remedies and enhancing regional competitiveness. The spillover effect of this cluster is of enormous and study of it will give some new dimensions and guidelines for the uplift of surgical instrument manufacturing industry. Based on the cluster-specific dimensions and prevalent issues of technical inefficiencies, our study will provide sort of out-of-the-box recommendations. We begin by research questions that this study would seek to explain. The rest of the article is organized as follows: overview of the relevant literature on technical efficiency, clustering and its impact on SMEs. Following that, we discuss the research methodology and explanation of the model and variables. In the next section, results of the study are explained. Conclusions, implications for policy makers, and recommendations for further study bring the discussion to a close. In this study, we seek to explain:

i. Are small and medium scale surgical instrument manufacturing enterprises of Sialkot working efficiently?

ii. What are the determinants and causal factors of technical efficiency in surgical instrument industry of Sialkot?

iii. What measures need to be taken to lessen the cost of doing business and attract potential entrepreneurs and international traders to boost such export-oriented clusters?

iv. Which scale to returns is prevalent in this cluster? Increasing, decreasing or constant?

v. How and what technological development to be inculcated in the surgical instruments cluster to retain its competitive edge?

\section{LITERATURE REVIEW}

\subsection{Technical Efficiency and Its Estimation}

Technical efficiency necessarily means no waste of material inputs and is considered to be a prerequisite for economic efficiency. Economic efficiency is achieved if the highest possible level of satisfaction is obtained from given resources. Because satisfaction is derived from consuming goods and services, economic efficiency requires the greatest possible level of production, that is, technical efficiency (Färe \& Lovell, 1978). A number of techniques have been developed to estimate this frontier. Several authors broadly classify them into two main groups: parametric and non-parametric (Coelli, Rao, O'Donnell, and Battese, 2005; Kalirajan \& Shand, 1999; Kumbhakar \& Lovell, 2003). Kleyn, Bekker, and Millard (2015) considered the Cobb-Douglas production function for investigation of South African manufacturing sector and found the restriction of constant returns to scale could not be rejected. Moreover, it was also revealed that the bounded linear exponential loss function outperforms the other loss functions across all the proposed parameters by comparing the risk values. Though Cobb-Douglas production function dates back to the work of Paul Douglas and Charles Cobb back in 1928, it is still a widely employed 
functional form in empirical analyses of production growth and estimating total factor productivity (Kleyn et al., 2015).

Various authors focused on South Asian and Southeast Asian countries to estimate the technical efficiency and thereby figure out its determinants. Sharma and Sharma (2010) analyzed the technical and scale efficiency of small industries in India in a state-wise cluster study, under the assumption of variable returns to scale, and revealed that most of the states were operating at decreasing returns to scale. Raj and Natrajan (2007) analyzed the level and sources of technical efficiency in the unorganized manufacturing sector of Indian state of Kerala using trans-log stochastic frontier production function. The findings showed high levels of technical inefficiency, which significantly reduce their potential levels, characterizing the unorganized manufacturing enterprises. It was further observed that size, ownership, and region cause significantly effect on technical efficiency level in most of the industrial groups. Baten, Rana, Das, and Khaleque (2006) analyzed the stochastic frontier production function in selected firms by using the panel data of manufacturing industries of Bangladesh, and the rate of increase in technical efficiency has been found to sluggish over time. Radam, Yacob, and Shah (2008) measured the technical efficiency of food industry in Malaysia by using the stochastic frontier model; the computed technical efficiency indices exhibited that the food industry under study was highly technical inefficient. Mahmood and Din (2007), by using the stochastic production frontier approach for periods 1995-96 and 2000-01, pointed outs several factors that might have caused a decline in the technical efficiency of firms e.g.; shortage of skilled labor, and high cost of lending. Tripathy (2006) identified the efficiency gap between foreign and domestic firms in eleven manufacturing industries of India during 1990-2000, using Cobb-Douglas stochastic production and cost frontier; the study concluded that the foreign firms are not using an appropriate technology. Likewise, Bhatt (2014) used the CobbDouglas production function, in order to derive the marginal productivity of SMEs of India, and found that labor is a better determinant of output than fixed capital. Age of the enterprise and proper working capital management were found to be significant determinants of productivity in an empirical study on the readymade garments' SMEs of Lahore, Pakistan (Ikram \& Su, 2015). It is imperative to note that the determinants of efficiency vary for large firms and SMEs; size is found to be an important determinant of technical efficiency; large firms found to be more efficient with respect to process and product innovation (Sanchez, DÃaz \& Rosario, 2014).

\subsection{Clustering and Its Impact on SMEs}

Marshal (1920) suggested that advantages arising from the concentration of related businesses in particular localities describe the benefits associated with the agglomeration economies. Literature has widely endorsed the benefits of industrial clusters and depicted that agglomeration of related businesses and small scale industry contributes to successful performance, especially, of small and medium enterprises (Engel \& del-Palacio, 2009; Porter, 1998; Rauch, Doorn, \& Hulsink, 2014; Ruan \& Zhang, 2009; Schmitz \& Nadvi, 1999). Clusters not only contribute to new business formation but also play significant role in survival of start-ups (Delgado, Porter, \& Stern, 2010). Start-ups usually face lower entry barriers and less risk of failure in industrial clusters, owing to the provision of infrastructure, easy access to suppliers, workforce and basic utilities (Ruan \& Zhang, 2009). Another remarkable fact that distinguishes business clusters in emerging economies from that of advanced nations is the abundance of workforce (Schmitz \& Nadvi, 1999). Long and Zhang (2011) advocated that cluster-based business model should be preferable choice for labor-intensive developing countries; and their investigation of Chinese industrial clusters revealed that SMEs grow more rapidly in industrial clusters than in non-clustered regions. Bellandi and Lombardi (2012) conducted fieldwork case studies in Zhejiang Province of China, and exhibited that provision of nearby specialized markets decreases cost of doing business and boosts growth of industrial clusters. Location-based complementarities can be realized through the creation of clusters. An empirical study of the ready-made garments SMEs of Lahore suggested localization economy is more facilitative for entrepreneurial growth as compared to urbanization economy (Ikram \& Su, 2015). Nadvi and Halder (2005), while investigating the Silakot surgical instruments cluster of Pakistan, also endorsed the implications of cluster strategy for SMEs. Though Nadvi (1999a, 1999b) has previously investigated Surgical instruments cluster of Sialkot with respect to collective efficiency and social networking aspects, and concluded that inter-firm relations and local relationship play significant role in the growth of this cluster, there is a need for recent study and empirical evidence with respect to technical efficiency for this particular cluster, thus we focused on the literature gap, specifically with respect to contributing industrial cluster. 


\subsection{Recent Developments and Prospects for Surgical Instruments Industry}

Recent literature discusses the widespread implications of 3D printing for manufacturing of surgical instruments (Kondor et al., 2013; Rankin et al, 2014; Schneider et al., 2015). Groundbreaking researches and cost efficiency have enhanced applications and accessibility of 3D printing for medical and surgical industry; the additive manufacturing is now viable for the industry of surgical instruments (Kondor et al., 2013). Manufacturing of surgical instruments asks for sterility, safety, strength and precision; now 3D Printing is fast progressing towards realizing these objectives. Rankin et al. (2014) developed Makerbot replicator for 3D printing of surgical instruments; and this device is quite energy efficient as well, so presents an ideal scenario for developing countries. Besides proposing the method of liquid phase 3D printing for rapid production of conductive metal objects, Wang and Liu (2014) also suggested the way to make prospective liquid phase 3D printer assimilated with syringe pump and needle arrays.

\section{RESEARCH METHODOLOGY \& HYPOTHESIS}

\subsection{Data Collection}

Data for empirical study was collected through survey questionnaire from 70 SMEs listed at Census of Manufacturing Industry $(\mathrm{CMI})^{1}$; covering the period 2012 - 2013. We approached 76 SMEs, out of which 6 enterprises did not reply and consequently we are left with the sample size of 70 SMEs, which signify a satisfactory overall response rate of $92 \%$. Stratified random sampling technique was employed in order to ensure representation of both the small and medium enterprises, and to filter out the large enterprises since they are beyond the scope of this study. Besides going with the survey findings, the study was also supplemented with direct observations of the researchers during fieldwork visits to come up with more pragmatic recommendations. For data analysis, in addition to descriptive statistics and regression analysis, we also performed stochastic frontier production estimation and various model diagnostic tests.

\subsection{Hypotheses}

a) $\mathrm{H}_{\mathrm{o}}: \delta_{0}=\delta_{1}=\delta_{2}=\delta_{3}=0$

The technical inefficiency effects are absent

b) $\mathrm{H}_{0}: \gamma=0$

Specifies that technical inefficiency effects are not random in industry

c) $\mathrm{H}_{\mathrm{o}}: \delta_{1}=0$

Indirect Inputs (imported and local) has no effect

d) $\mathrm{H}_{0}: \delta_{2}=0$

There is no effect of age of firm on productivity

e) $\mathrm{H}_{\mathrm{o}}: \delta_{3}=0$

There are no ownership variations

f) $\mathrm{H}_{\mathrm{o}}: \beta_{1}+\beta_{2}+\beta_{3}=1$

There is a constant return to scale

\footnotetext{
${ }^{1}$ The CMI is being conducted by Bureau of Statistics (BoS) and Federal Bureau of Statistics (FBS), Pakistan; it provides basic statistics with respect to manufacturing establishments in Pakistan.
} 


\subsection{Basic Model to Estimate Technical Efficiency}

Kalirajan and Shand (1999) defined the measure of technical efficiency in the $i$ th firm as:

Where,

$$
\text { Technical Efficiency }(T E)=\frac{Y_{i}}{Y_{i}^{*}}
$$

$\mathrm{Y}_{i}$ indicates the actual output, and

$\mathrm{Y}_{i}^{*}$ indicates the utmost viable output

The aforementioned equation is regarded as the basic model to estimate technical efficiency, provided the actual output is observable. By utmost viable output, we meant the enterprise is technically efficient and operates on the production frontier.

\subsection{Model and Variables}

Though there are various options available with respect to functional form of the production frontier, but given the specifications of the corresponding translog frontier model, Cobb-Douglas (CD) production function found to be an adequate representation of the data. In this study, CD model will be further modified to translog linear function form for estimating the unknown parameters by ordinary least square (OLS) method:

$$
Y_{i}=\beta_{0}\left(L_{i}\right)^{\beta_{1}}\left(K_{i}\right)^{\beta_{2}}\left(M_{i}\right)^{\beta_{3}} u_{i}
$$

The log linear form of model (A) will be:

$$
\operatorname{Ln}\left(Y_{i}\right)=\beta_{0}+\beta_{1} \operatorname{Ln}\left(L_{i}\right)+\beta_{2}\left(K_{i}\right)+\beta_{3}\left(M_{i}\right)+v_{i}+u_{i}
$$

Where,

$$
\begin{aligned}
& Y_{i}=\text { Output of firm } i \\
& K_{i}=\text { Value of Capital of firm } i \\
& L_{i}=\text { Labour input of firm } i \\
& M_{i}=\text { Materials used at intermediate and primary levels } \\
& v_{i}=\text { Random error in which } v i \sim N\left(0, \sigma^{2}{ }_{v}\right) \\
& u_{i}=\text { Technical inefficiency in which } u i \sim N\left(\mu i, \sigma^{2}{ }^{2}\right)
\end{aligned}
$$

In order to estimate the inefficiency of $i^{\text {th }}$ firm in terms of a vector of firm specific variables, and the vector of associated parameter, $\delta$, along with the parameters of frontier production function through a single stage maximum likelihood method, the technical inefficiency is written as:

$$
\mu_{i}=\delta^{\prime} z_{i}
$$

Where $\delta^{\prime}$ is the transpose of $\delta$. This type of specification can be obtained from density function of $u_{i}$ conditional on $\varepsilon_{i}=v_{i}-u_{i}$ as well as the expected value of $T E_{i}$. To find out the determinants of Technical Efficiency, $u_{i}$ is modeled as under:

$$
\mu_{i}=\delta_{0}+\delta_{1} \operatorname{Ln} I_{i}+\delta_{2} \operatorname{Ln} \mathrm{Age}_{i}+\delta_{3} \operatorname{LnOn_{i}}+D_{i}
$$


Where,

$A g e_{i}=$ Difference between the current year and firm's initial production year

$I_{i}=$ Intermediate inputs of $i^{\text {th }}$ firm

$O n_{i}=$ the status of ownership of the firm, private or state owned / others. Owing to its qualitative nature, it is a dummy variable; where, value ' 1 ' represents private owned firms and ' 0 ' value denotes government owned or others firms.

$\delta$ 's are the parameters to Scale (CRS) in the small and medium surgical manufacturing enterprises.

\subsection{Explanation of Variables}

The variables used in the study are composed of different entities and sub variables. It was virtually not possible to get perfect value for any variable, thus we employed few sub-variables to compose them into a single variable. The compositions of variables are as following:

3.5.1 Output $(Y)$ The Cob-Douglas production function is being used to evaluate the production; Output $(\mathrm{Y})$ is taken as a dependent variable in (1) and it constitutes:

a) Value of sales from own production (finished goods)

b) Value of sales for semi-finished product

3.5.2 Labor $(L)$ is independent variable in this study, as defined in (1).

3.5.3 Capital $(K)$ has different dimensions but in this study it is being used to represent all fixed assets, buildings, machinery and liquid form of money.

3.5.4 Age of firm $(A G)$ is being used in unit form.

3.5.5 Materials include raw and semi-finished materials, assembly parts etc., which are physically incorporated in the products and by-products mode. It also take in chemicals and packing materials which are consumed in the production. Raw-materials which are subcontracted to another enterprise for manufacturing goods are taken into consideration, whereas raw-materials delivered by others for processing on their behalf are excluded.

3.5.6 Other Inputs are categorized under the variable 'Inputs (I)', and includes the following:

a) Non-industrial cost consists of payments for transport, insurance, copy rights/royalties, postage, telegraph charges, stationary costs, advertising expenses, traveling expenses, legal expenses and other such expenses incurred by the establishment.

b) Financial expenditure includes mark-up paid on long term and short-term loans, payment for bank charges, payment for worker's welfare fund, loss on the sale of fixed assets and other financial expenditures of the enterprise.

\section{DESCRIPTIVE ANALYSIS}

The descriptive statistics and correlation matrix of Output (Y), Labor (L), Capital (K), Material (ME), Indirect Inputs (IP) and Age (AG) of the firm are given in Table 4.1 and Table 4.2 respectively. 
Table 4.1 Descriptive Statistics

\begin{tabular}{l|c|c|c|c|c|c}
\hline & Output & Labor & Capital & Material & Indirect inputs & Age \\
\hline Mean & 75422.59 & 67.38571 & 31349.11 & 43233.44 & 53102.06 & 19.85714 \\
\hline Median & 23983.00 & 22.50000 & 5097.500 & 11797.50 & 17361.00 & 18.50000 \\
\hline Maximum & 590390.0 & 589.0000 & 832174.0 & 499654.0 & 539358.0 & 49.00000 \\
\hline Minimum & 210.0000 & 6.000000 & 50.00000 & 654.0000 & 939.0000 & 5.000000 \\
\hline Std. Dev. & 118899.4 & 117.4233 & 104600.7 & 77859.42 & 90694.83 & 10.59161 \\
\hline Sum & 5279581. & 4717.000 & 2194438. & 3026341. & 3717144. & 1390.000 \\
\hline
\end{tabular}

Table 4.1 depicts that average output is 75423 units in small and medium surgical instrument cluster of Sialkot, and the average age of the industry is around 20 years. Similarly, other variables are also exhibited. Correlation among all the variables is shown in Table 4.2. Though the correlation values for dependent variables should ideally be less than 0.5 to fulfill multi-collinearity test, they are marginally higher in our study. Considering the pragmatic approach and roller coaster economic environment, this slight inconsistency is understandable.

Table 4.2 Correlation Matrix between Logarithmic values of Y, L, K, Me

\begin{tabular}{l|c|c|c|c}
\hline & Ln_Y & Ln_L & Ln_K & Ln_ME \\
\hline $\boldsymbol{L n}$ _Y & 1.0000 & - & - & - \\
\hline $\boldsymbol{L n}$ _L & 0.5207 & 1.0000 & - & - \\
\hline $\boldsymbol{L n}$ _K & 0.5121 & 0.5003 & 1.0000 & - \\
\hline $\boldsymbol{L n}$ _ME & 0.4999 & 0.4102 & 0.5235 & 1.0000 \\
\hline
\end{tabular}

\subsection{Model Estimation and Interpretation}

The following model is opted for this study:

$$
Y_{i}=\beta_{0}\left(L_{i}\right)^{\beta_{1}}\left(K_{i}\right)^{\beta_{2}}\left(M_{i}\right)^{\beta_{3}} u_{i}
$$

As we have to estimate the above model, the aforementioned model will take the linear form:

$$
\operatorname{Ln}\left(Y_{i}\right)=\beta_{0}+\beta_{1} \operatorname{Ln}\left(L_{i}\right)+\beta_{2}\left(K_{i}\right)+\beta_{3}\left(M_{i}\right)+v_{i}
$$

The estimation of above equation and unknown $\beta$ 's are exhibited in Table 4.3. Putting values from Table 4.3 into linear equation, the estimated form of model will be:

$$
\operatorname{Ln}(\mathrm{Y})=1.4468+0.2435 \operatorname{Ln}(\mathrm{L})+0.0476 \operatorname{Ln}(\mathrm{K})+0.7797 \operatorname{Ln}(\mathrm{M})
$$

And the standard form of this Cobb- Douglas model is:

$$
\mathrm{Y}=1.4468(\mathrm{~L})^{0.243527}(\mathrm{~K})^{0.047627}(\mathrm{M})^{0.779769}
$$

Table 4.3 Estimation of Coefficients, Standard Errors and P-Value

\begin{tabular}{l|c|c|c|c}
\hline \multicolumn{1}{c|}{ Variable } & Coefficient & Std. Error & t-Statistic & Prob. (P-value) \\
\hline $\boldsymbol{\beta}_{\mathbf{0}}$ & 1.4467 & 0.5187 & 2.7891 & 0.0069 \\
\hline $\boldsymbol{L n}$ _L & 0.2435 & 0.1047 & 2.3244 & 0.0232 \\
\hline $\boldsymbol{L n}$ _K & 0.0476 & 0.0533 & 0.8933 & 0.3749 \\
\hline
\end{tabular}

\subsection{Other Estimates and Test of Goodness}

In order to strengthen the findings of the study and evaluate the fitness of the model, we performed few other goodness tests as well. Some important findings of an econometric model are exhibited in Table 4.4. The values of $\mathrm{R}^{2}$, standard error of regression, sum of square of residuals, Durbin Watson test and F-Statistic, endorse the fitness of our model and thereby the findings of the study can be considered rigorous. The estimation of these goodness tests are explained in detail in the next section. 
Table 4.4 Estimation results of various tests

\begin{tabular}{c|l|c}
\hline Sr. \# & \multicolumn{1}{|c}{ Name } & Statistics \\
\hline 1 & R-squared & 0.8645 \\
\hline 2 & Adjusted R-squared & 0.8583 \\
\hline 3 & S.E. of regression & 0.5978 \\
\hline 4 & Sum squared residuals & 23.589 \\
\hline 5 & Durbin-Watson stat & 2.0940 \\
\hline \multirow{2}{*}{6} & F-statistic & 140.42 \\
& Prob (F-statistic) & 0.0000 \\
\hline
\end{tabular}

\subsection{Interpretation of the Results}

\subsubsection{Model 4}

The estimated model shows the intercept value of the model is 1.4468 which necessarily means the effect on output of variables, other than those narrated variables in the model, is 1.4468 and its positive sign indicates that it has intercept on y-axis. Keeping other variables constant, one unit change in labor input will bring 0.2435 unit positive change in output. In a way, the positive relationship between labor and output is a good sign; it shows that there is potential available to accommodate labor force, and increase in labor will be beneficial with respect to output. However one needs to careful, as increase in labor beyond certain point can lead to the adverse implications of law of diminishing returns and this needs to be studied further. As expected, the relationship between capital and output is also positive. Important aspect to note over here is that coefficient value for capital (0.0476) is substantially less than the coefficient value for labor (0.2435). This is understandable as surgical instrument manufacturing is primarily labor-intensive and more dependent on the artisanship than machinery. Regarding the role of materials and energy inputs, one unit change in materials input is shown to bring about 0.7798 positive change in output. It can be further observed that overall it is an increasing function, and the strongest effect on output is from material and energy inputs.

\subsubsection{Model 5}

This is standard form of Cobb-Doulas production function, and the purpose of this model is to estimate the degree of each input towards output. In equation 5, the value of 1.4468 indicates total-factor productivity (TFP) and represents the effect in total output that is not occurred because of given inputs. The power of labor (L) 0.243527 shows the intensity of labor towards output (Y) and this value can also be called elasticity of labor, which necessarily means the effect of additional unit of labor on output. Likewise, the power of capital (K) is 0.047627, which displays the intensity of capital towards output and represents the elasticity of capital. Same is the case with Material and Energy (ME).

\subsubsection{Interpretation of $R^{2}$ and Adjusted $R^{2}$}

$\mathrm{R}^{2}$ is a statistic which suggests about the goodness of fit for a model. The value of $\mathrm{R}^{2}$, i.e. 0.8646 , shows that the model is near to perfectly fit to the data and more than $86 \%$ of the variation has been explained in this model. Moreover, Figure 1 graphically endorses goodness of fir for the model and describes that all the calculated values lie near the curve, estimated curve and the calculated line. 
Figure 1. Graphic Interpretation of R2 and adjusted R2

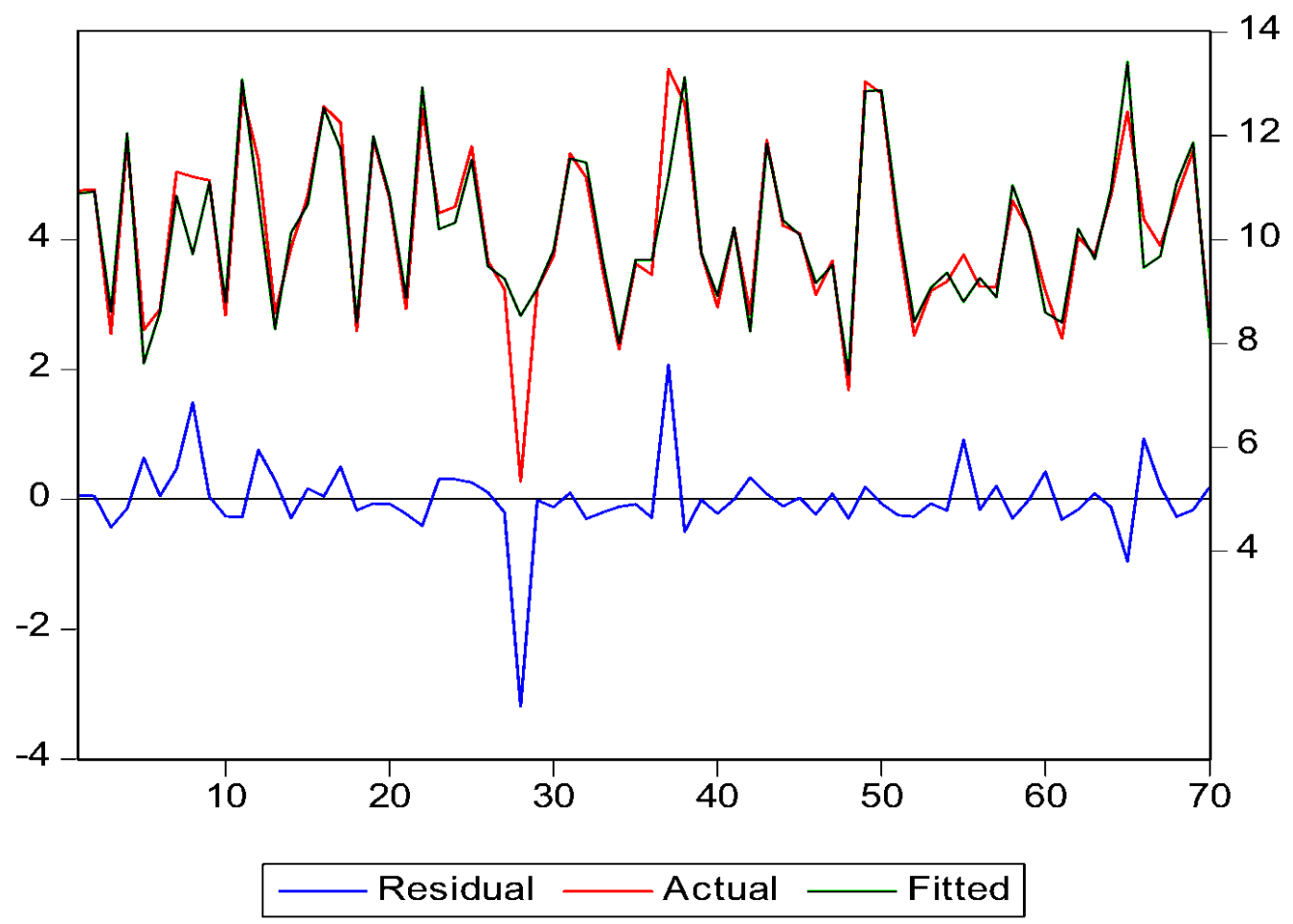

5. RESULTS

The coefficient of Labor (L), $\beta_{I}=1.43633$, is found to significant (i.e. P-value $=0.0069<\alpha=5 \%$ ); which implies that $\beta_{1}$ is significant, thus labor has significant effect on output. Meanwhile, coefficient of Capital (K), $\beta_{2}=0.04614$, is found to be insignificant in this model, as $\mathrm{P}$-Value 0.3749 is greater than $\alpha$ value of $5 \%$ (i.e. P-Value $>\alpha$ ). This does not mean that the role of capital is not imperative in small and medium surgical manufacturing enterprises; rather this shows the value of capital is found to be statistically insignificant in this study. Labor-intensive nature of the industrial cluster under study is perhaps the main reason for the insignificance of 'capital' variable. This could be attributed various reasons, such as miscommunication on the part of respondents while giving information owing to taxes.

In the case of $\beta_{3}=0.7749$, the P-Value $=0.0000$ is less than $\alpha$ for all levels of significance. Thus $\beta_{3}$ is found to be significant, which implies that material has significant positive effect on output. Table 5.1 exhibits that all the variables, with the exception of capital, being used in the study have significant effect on productivity. The overall model is fit and correctly specified as exhibited in row 5 of Table 5.1, thus we can say that the parameters being used in the model are comprehensively explaining the study problem. 
Table 5.1 Estimation results for Stochastic Frontier Production Function and OLS, for the SMEs of cluster

\begin{tabular}{|c|c|c|c|c|c|c|c|}
\hline \multirow[b]{2}{*}{$\begin{array}{l}\text { Sr. } \\
\text { No. }\end{array}$} & \multirow[b]{2}{*}{ Variables } & \multicolumn{3}{|c|}{ Stochastic Frontier Production Estimation } & \multicolumn{2}{|c|}{ OLS Estimation } & \multirow[b]{2}{*}{$\begin{array}{c}\text { Decisions } \\
(\alpha=5 \%)\end{array}$} \\
\hline & & Parameters & $\begin{array}{c}\text { Standard } \\
\text { Error }\end{array}$ & T-Value & Parameters & P-Value & \\
\hline 1 & Constant $\left(\beta_{0}\right)$ & 1.4363 & 0.5187 & 2.7891 & 1.4468 & 0.0069 & Significance \\
\hline 2 & Labour (L) & 0.2270 & 0.1048 & 2.3244 & 0.2435 & 0.0232 & Significance \\
\hline 3 & Capital (K) & 0.0461 & 0.0533 & 0.8934 & 0.0476 & 0.3749 & Insignificance \\
\hline 4 & Material $(\mathrm{Me})$ & 0.7749 & 0.0782 & 1.9656 & 0.7798 & 0.0000 & Significance \\
\hline 5 & $\operatorname{Prob}(F$-statistic) & & & & 140.4262 & 0.0000 & $\begin{array}{l}\text { Over all } \\
\text { Significance }\end{array}$ \\
\hline
\end{tabular}

\section{Inefficiency Model}

\begin{tabular}{c|l|l|l|l|l|l|l}
\multicolumn{1}{l}{ Inefficiency Model } & & & -- & -- \\
\hline 6 & $\delta_{0}$ & 9.5560 & 0.6013 & 0.6959 & -- & -- & - \\
\hline 7 & Inputs (intermediate) $\delta_{1}$ & -0.8048 & 0.0475 & 0.6212 & -- & -- & - \\
\hline 8 & Age $\delta_{2}$ & -0.0064 & 0.1258 & 0.2782 & -- & - \\
\hline 9 & Ownership (Dummy) $\delta_{3}$ & -0.1134 & 0.3521 & 0.2329 & -- & - & - \\
\hline
\end{tabular}

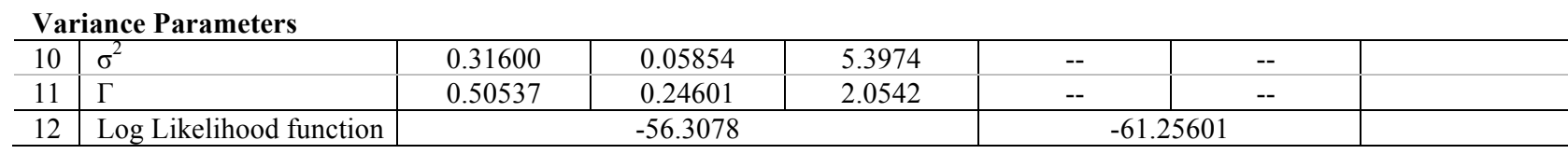

\section{Testing of Hypotheses (Table 5.2)}

The logarithm values for the likelihood function of Cobb Douglas Production Model are -61.2560 and -56.3078 (see Table 5.1 and Table 5.2), resultantly the generalized likelihood ratio test statistic is 94.3296 .

i. Absence of technical inefficiency effect

Ho: $\delta_{0}=\delta_{1}=\delta_{2}=\delta_{3}=0$

By imposing the restriction on original model, the value of log likelihood function becomes -56.3080 . The test statistic on the basis of generalized likelihood ratio statistic is 94.3296 , which is greater than the critical values of $9.488-13.277$ at $1 \%$ and $5 \%$ level of significance respectively. So we fail to accept the null hypothesis of no technical inefficiency effects and conclude that there is prevalence of technical inefficiencies in this particular industrial cluster of surgical instruments:

LR test $=-2\left[\ln \mathrm{L}\left(\mathrm{H}_{0}\right)-\ln \mathrm{L}\left(\mathrm{H}_{1}\right)\right]$

$-2[(-56.3078+9.143)]$

$-2(-47.1648)$

$\mathrm{LR}=94.3296$

ii. Technical inefficiency effects are not random in industry $($ Ho: $\gamma=0)$

The variance of the technical inefficiency effect will be zero when parameter $\gamma$ is zero, and the subsequent model moderates to the traditional mean response function in which the labor, capital, material, age of the firm, indirect inputs and ownership (dummy) variables are included in the production function. However, provided the production function has an intercept and parameter $\gamma$ is not equal to zero, then the $\delta_{0}$ parameter is not identified. The value of generalized log likelihood, i.e. 15.6360 , is greater than the critical values of $3.840-6.663$ at both $1 \%$ and $5 \%$ levels of significance respectively. Thus we reject the null hypothesis and conclude that technical inefficiency effects are of random nature.

LR test $=-2[(-16.961+9.143)]$

$\mathrm{LR}=15.636$ 
Table 5.2 Hypothesis testing for parameters of Stochastic Frontier and Inefficiency Model

\begin{tabular}{c|l|c|c|c|c}
\hline $\begin{array}{c}\text { Sr. } \\
\text { No. }\end{array}$ & \multicolumn{1}{|c|}{ Hypothesis } & $\begin{array}{c}\text { Log Likelihood } \\
\text { Statistics }\end{array}$ & Test Statistics & $\begin{array}{c}\text { Critical values } \\
(\boldsymbol{\alpha}=\mathbf{1 \%} \text { \& 5\%) }\end{array}$ & Decision \\
\hline 1 & Ho: $\delta_{0}=\delta_{1}=\delta_{2}=\delta_{3}=0$ & -56.3080 & 94.3296 & $9.488-13.277$ & Reject Ho \\
\hline 2 & Ho: $\gamma=0$ & -16.9608 & 15.6360 & $3.840-6.663$ & Reject Ho \\
\hline 3 & Ho: $\delta_{1}=0$ & -14.001 & 9.7160 & $7.810-11.34$ & Reject Ho \\
\hline 4 & Ho: $\delta_{2}=0$ & -11.0019 & 3.7078 & $7.810-11.34$ & Accept Ho \\
\hline 5 & Ho: $\delta_{3}=0$ & -10.2036 & 2.1220 & $7.810-11.34$ & Accept Ho \\
\hline 6 & Ho: $\beta_{1}+\beta_{2}+\beta_{3}=1$ & -56.308 & 1.32 & $3.84(\alpha=5 \%)$ & Accept Ho \\
\hline
\end{tabular}

iii. Indirect inputs (imported and local) have no effect

The third null hypothesis is related to the effects of firm specific factors on technical inefficiency of firms. The null hypothesis is shown as under:

Ho: $\delta_{1}=0$

By imposing this restriction on inefficiency model the value of the log likelihood function is -14.001 . The generalized likelihood test statistic found out to be 9.7160 , which is greater than the critical values at both $1 \%$ and $5 \%$ level of significance. Therefore, we again fail to accept the null hypothesis and conclude that indirect inputs (imported and local) are imperative for surgical manufacturing instrument enterprises.

LR test $=-2\left[\ln \mathrm{L}\left(\mathrm{H}_{0}\right)-\ln \mathrm{L}\left(\mathrm{H}_{1}\right)\right]$
$-2[(-14.001+9.143)]$
$\mathrm{LR}=9.716$

iv. $\quad$ No age effect $\left(\mathrm{Ho}: \delta_{2}=0\right)$

The values for log likelihood function and generalized likelihood test statistic are -11.0019 and 3.7078, respectively. From Table 5.2, we can observe that this statistic is less than the critical values at $1 \%$ and $5 \%$ level of significance. Therefore, we accept null hypothesis of no age effect and conclude that age of firm does not significantly affect productivity in the industrial cluster under study:

LR test $=-2[(-11.0019+9.143)]$

$\mathrm{LR}=3.7078$

v. $\quad$ There are no ownership variations

The fifth null hypothesis states that there would be no ownership variations on technical inefficiency. The null hypothesis is as follows:

Ho: $\delta_{3}=0$

By imposing this restriction on inefficiency model, the value of the log likelihood function is -10.2036 , and the generalized likelihood test statistic is calculated as 2.122. Since this statistic is less than the critical values at both $1 \%$ and 5\% level of significance, we fail to reject null hypothesis and conclude there would be no ownership variation effect on the efficiency of surgical instrument manufacturing enterprises of the cluster.

LR test $=-2[(-10.204+9.143)]$

$\mathrm{LR}=2.122$ 


\section{vi. $\quad$ There is a Constant Return to Scale (CRS)}

$$
\text { Ho: } \beta_{1}+\beta_{2}+\beta_{3}=1
$$

By imposing the aforementioned restriction on the model, the value for logarithm of likelihood function becomes 56.308. Since the test statistic of 1.34 is less than the critical value of 3.84 at $5 \%$ level of significance, the null hypothesis is not rejected and it can therefore be concluded that there exists constant returns to scale for the sample study under consideration. For proof, we add all the coefficients of our input variables:

$$
\begin{aligned}
& \beta_{1}+\beta_{2}+\beta_{3}=0.2270+0.0461+0.7749 \\
& \beta_{1}+\beta_{2}+\beta_{3}=1.048
\end{aligned}
$$

\section{CONCLUSIONS, RECOMMENDATIONS AND FUTURE STUDY}

The study not only highlighted the significant determinants of technical efficiency, but also emphasized the advantages of industrial cluster. Technical inefficiency effects are present and contain a significant random component. The Sialkot surgical instruments cluster as a whole is not operating on technically efficient level; and indirect inputs, labor, material and energy are found to be significant determinants of technical efficiency. The joint effect of explanatory variables is significant in minimizing the technical inefficiencies of small and medium surgical instrument manufacturers. Although individual impact of some of the variables, like capital, is found to be insignificant. Since constant returns to scale are prevalent in small and medium surgical instrument manufacturing cluster of Sialkot, there is little scope for increasing production by increasing all the inputs in the same proportion. Labor and material showed significant positive impact on output, thus increasing labor might be beneficial for the output of the enterprise as a whole. However, caution needs to be taken, as increase in labor beyond certain point can lead to reduced productivity as our study also suggests prevalence of constant returns to scale. The insufficiency of productivity can be virtually wholly attributed to technical inefficiency and it is further advocated that by reducing the prevailing technical inefficiency in this urbanization economy, productivity can be enhanced by as much as 5.6\%. Interestingly, age of enterprises is not shown to have significant impact on productivity; which, in a way, is a positive sign for nascent enterprises. If the prospective entrepreneurs fully capitalize on labor and input resources, they can achieve supply chain excellence and establish thriving start-ups.

This is necessarily an urbanization economy as $99 \%$ manufacturing units of surgical instruments are located in 25 KM radius of Sialkot district; thus this industrial cluster can be boosted and assisted in a more efficient and coordinated manner. On the basis of this study and empirical results thereof, it is recommended that the inefficiency effect must be countered with effective techniques and policies. The major inefficiency is found in indirect inputs and mostly those inputs which are imported from other countries. Government and relevant institutions need to create incubator centers and ensure the provision of inputs. It was also observed that financial institutions hesitate in sanctioning loans for new enterprises, so there is a need to facilitate potential entrepreneurs by promoting the concept of seed investors and angel investors. There is less focus on research and development, thus most enterprises are found to be imitators rather than innovators. Considering the revolutionary implications of 3D printing for manufacturing of surgical and dentistry instruments (Schneider et al., 2015; Rankin et al., 2014) and recent innovations in 3D metal printing and Makerboot replica (Rankin et al., 2014; Wang \& Liu, 2014), stakeholders should keep themselves abreast with technological developments and are advised to be futuristic in applying additive manufacturing sooner rather than later in order to sustain and enhance the regional competitive edge. Since most of the businesses of the cluster are small and medium enterprises, collaborative environment and strategic sourcing will help in reducing technical inefficiency of this export-oriented industry. We recommend 'triple-helix +1 ' model for this particular surgical instruments cluster, whereby in addition to traditional triple-helix model (i.e. collaboration among government, industry and academia); local community is encompassed in the innovation nexus. Social networking and local sources of competitiveness, based on family and localness, are long found to be of paramount importance in the surgical instrument cluster of Sialkot (Nadvi, 1999a \& b), thus systematic inclusion of local community in triple helix framework will be beneficial. Finally, establishment of specialized markets or trading cities, for final products and raw-material, is proposed to boost the industrial cluster and lure in international traders of surgical instruments; this pattern of specialized market in proximity to cluster has 
been widely successful in China, often referred to as 'Zhejiang model', and thus merits to be benchmarked (Bellandi \& Lombardi, 2012; Long \& Zhang, 2011; Ruan \& Zhang, 2009). Since it was found that proper supply of indirect inputs is of paramount importance for this sector, the availability of specialized market for raw-material and machinery in proximity with the industry will be beneficial for the productivity of this sector. Specialized markets for intermediary products will not only allow the proper supply of inputs and raw-material, but also caters to the problem of inventory management by allowing sort of the just-in-time inventory system. The resultant realignment of operating practices by way of proximity of specialized markets for inputs will help in reducing waste and will persuade enterprises to go lean.

Implications for cluster-based industries are imperative for regional development, especially of developing economies. Various researchers investigated the surgical instruments cluster but hardly any of them evaluated the aspect of technical efficiency, our other contemporary contribution is cluster-specific recommendation of 'triplehelix +1 model'. Incorporating these concepts into future research has the potential to improve our understanding of how cluster strategy helps in achieving technical efficacy and how to internationalize industrial clusters. We end our article with numerous directions for future researchers. (a) This study is based on SMEs manufacturing surgical instruments, larger scale manufacturing units can also be taken into consideration in order to broaden the horizon of the study and improve generalizability. (b) Pragmatic steps to rectify prevalent technical inefficiencies should be researched further, and energy crisis of Pakistan should be taken into consideration. (c) Since it is an export-oriented cluster, a study of global supply chain and logistics management is also recommended. (d) For the purpose of regional planning and development, a similar study is suggested to be conducted on the reputed sports cluster of Sialkot, lying in the close proximity to surgical instruments cluster.

\section{AUTHOR BIOGRAPHIES}

Amir Ikram is Ph.D. scholar at School of Management, Xi'an Jiaotong University, China. His interests lie in entrepreneurship, additive manufacturing, cluster strategy and regional development. Having more than 5 years of teaching experience at university level, he is also serving as an instructor at NCBA\&E, Lahore (Pakistan). amirikram12@hotmail.com

Dr. Qin Su is doctoral tutor and department head at School of Management, Xi'an Jiaotong University. Her research interests include quality management, industrial engineering, and enterprise management. She has authored more than 150 peer-reviewed articles in leading international journals. qinsu@mail.xjtu.edu.cn (Corresponding author)

Muhammad Asif Sadiq is education manager at GC University Lahore, Pakistan. He is also serving as visiting faculty member at various private and public sector institutions of Lahore, Pakistan for more than 7 years. His research interests are related to econometrics, entrepreneurship and economic development. asifsadiq_17@hotmail.com

\section{ACKNOWLEDGEMENT}

The authors are thankful to "National Natural Science Foundation of China, Project Number: 71371151" for research support. The research contribution has also been supported by "Humanities and Social Sciences of Ministry of Education Planning Fund (13YJA630078)".

\section{REFERENCES}

Ahmed, A. (2010). Pakistan Surgical Industry; Structure, Issues / Problems \& Recommendations. The Rawalpindi Chamber of Commerce \& Industry, 4-2.

Baten, M. A., Rana, M., Das, S., \& Khaleque, M. A. (2006). Technical efficiency of some selected manufacturing industries in Bangladesh: a stochastic frontier analysis. Lahore Journal of Economics, 11(2), 23-41.

Bellandi, M., \& Lombardi, S. (2012). Specialized markets and Chinese industrial clusters: The experience of Zhejiang Province. China Economic Review, 626-637.

Bhatt, N. J. (2014). Productivity in Small and Medium Enterprises of India: A Cobb-Douglas Production Function Approach. IUP Journal of Management Research, 13(1), 29. 
Coelli, T. J., Rao, D. S. P., O'Donnell, C. J., \& Battese, G. E. (2005). An introduction to efficiency and productivity analysis. Springer Science \& Business Media.

Engel, J. S., \& del-Palacio, I. (2009). Global networks of clusters of innovation: Accelerating the innovation process. Business Horizons, 493-503.

Färe, R., \& Lovell, C. K. (1978). Measuring the technical efficiency of production. Journal of Economic theory, 19(1), $150-162$.

Ikram, A., \& Su, Q. (2015). Determinants of Productivity in the Ready-made Garments SMEs of Lahore, Pakistan. In Proceedings of the 5th International Asia Conference on Industrial Engineering and Management Innovation (IEMI2014), 81-86. Atlantis Press.

Kalirajan, K. P., \& Shand, R. T. (1999). Frontier production functions and technical efficiency measures. Journal of Economic surveys, 13(2), 149-172.

Kleyn, J., Arashi, M., Bekker, A., \& Millard, S. (2015), Preliminary Testing of the Cobb-Douglas Production Function and Related Inferential Issues. Communications in Statistics-Simulation and Computation, 00-00.

Kondor, S., Grant, C. G., Liacouras, P., Schmid, M. J. R., Parsons, L. M., Rastogi, V. K., ... \& Macedonia, C. (2013). On demand additive manufacturing of a basic surgical kit. Journal of Medical Devices, 7(3), 030916.

Krugman, P. (1991). Geography and trade: MIT Press, Cambridge, MA, 85.

Kumbhakar, S. C., \& Lovell, C. K. (2003). Stochastic frontier analysis. Cambridge University Press.

Liker, J. K., \& Choi, T. Y. (2004). Building deep supplier relationships. Harvard business review, 82(12), 104-113.

Long, C., \& Zhang, X. (2011). Patterns of China's industrialization: Concentration, specialization,. China Economic Review, 593612.

Mahmood, T., Ghani, E., \& Din, M. U. (2006). Efficiency of Large-scale Manufacturing in Pakistan: A Production Frontier Approach. The Pakistan Development Review, 689-700.

Marshall. (1920). Principles of Economics. Macmillan, London.

Nadvi, K. (1999a). Shifting ties: social networks in the surgical instrument cluster of Sialkot, Pakistan. Development and Change, 30(1), 141-175.

Nadvi, K. (1999b). Collective efficiency and collective failure: the response of the Sialkot surgical instrument cluster to global quality pressures. World development, 27(9), 1605-1626.

Nadvi, K., \& Halder, G. (2005). Local clusters in global value chains: exploring dynamic linkages between Germany and Pakistan. Entrepreneurship \& Regional Development, 17(5), 339-363.

Pakistan Tourism Development Corporation, (2013). Sialkot. Retrieved from http://www.tourism.gov.pk/sial.htm

Porter, M. E. (1998). Clusters and the new economics of competition. Harvard Business Review, 76(6), 77-90.

Radam, A., Yacob, M. R., \& Shah, S. A. K. (2008). The Technical Efficiency of Food Industry in Malaysia: An Application of Stochastic Frontier Model. International Applied Economics and Management Letters, 1(1), 19-23.

Rankin, T. M., Giovinco, N. A., Cucher, D. J., Watts, G., Hurwitz, B., \& Armstrong, D. G. (2014). Three-dimensional printing surgical instruments: are we there yet?. Journal of Surgical Research, 189(2), 193-197.

Raj, R., \& Natarajan, S. (2007). Technical Efficiency in the Informal Manufacturing Enterprises: Firm level evidence from an Indian state.

Ruan, J., \& Zhang, X. (2009). Finance and cluster-based industrial development in China. Economic Development and Cultural Change, 58, 143-164.

Sanchez, R., Díaz, M.A., \& Rosario, S. Ã. (2014). Innovation, exports and technical efficiency in Spain (No. 6783). EcoMod.

Schmitz, H., \& Nadvi, K. (1999). Clustering and industrialization: introduction. World development, 27(9), $1503-1514$.

Schneider, D., Schober, F., Grohmann, P., Hammerle, C. H., \& Jung, R. E. (2015). In-vitro evaluation of the tolerance of surgical instruments in templates for computer-assisted guided implantology produced by 3 -D printing. Clinical oral implants research, 26(3), 320-325.

Sharma, S., \& Sharma, M. (2010). Analyzing the technical and scale efficiency of small industries in India: state-wise cluster study. Measuring Business Excellence, 14(2), 54-65.

Surgical Instruments Manufacturers Association of Pakistan (2015, July). Monthly Bulletin. Retrieved from http://www.simap.org.pk/

Tripathy, S. (2006). Are Foreign Firms Allocatively Inefficient?: A study of selected manufacturing industries in India. In $5^{\text {th }}$ Annual GEP Postgraduate Conference (Leverhulme Centre for Research on Globalisation and Economic Policy (GEP), Nottingham.

UN Comtrade. (2014). UN Surgical and Medical Trade Statistics of Pakistan. Retrieved from http://comtrade.un.org/db/dqBasicQueryResults.aspx?px=HS\&cc=9018,841920,901890\&r $=$ $586 \& \mathrm{p}=0 \& \mathrm{rg}=2 \& \mathrm{y}=2014,2013,2012,2011,2010 \& \mathrm{so}=8$

Wang, L., \& Liu, J. (2014). Liquid phase 3D printing for quickly manufacturing conductive metal objects with low melting point alloy ink. Science China Technological Sciences, 57(9), 1721-1728.

World Bank Flagship Report. (2016). Doing Business 2016; Measuring Regulatory Quality and Efficiency, 5. Retrieved from http://www.doingbusiness.org/ /media/GIAWB/ Doing\%20Business/Documents/Annual-Reports/English/DB16-FullReport.pdf 